\title{
Impact of Nanotechnology and its application in Construction
}

\author{
Dr. Preeti Singh Bahadur ${ }^{1} \mid$ Harshit Srivastava $^{2} \mid$ Dr. Shalini Jaiswal ${ }^{3}$ \\ ${ }^{1}$ Physics, Amity University, Greater Noida(U.P) \\ ${ }^{2}$ Civil Engineering, Amity University, Greater Noida(U.P) \\ ${ }^{3}$ Chemistry, Amity University, Greater Noida(U.P)
}

\section{To Cite this Article}

Dr. Preeti Singh Bahadur, Harshit Srivastava and Dr. Shalini Jaiswal, "Impact of Nanotechnology and its application in Construction", International Journal for Modern Trends in Science and Technology, Vol. 06, Issue 07, July 2020, pp.:01-09; https://doi.org/10.46501/IJMTST060701

\section{Article Info}

Received on 22-May-2020, Revised on 22-June-2020, Accepted on 25-June-2020, Published on 27-June-2020.

\section{ABSTRACT}

The innovation of relevant nanotechnology and its significance in civil engineering practice is illustrated in this paper for broadening vision. Nanotechnology deals with understanding, controlling and manipulating matter at the level of individual atoms and molecules in the range of $0.1-100 \mathrm{~nm}(10-9 \mathrm{~m})$. It creates materials, devices, and systems with new properties and functions. The role of nanotechnology in the conceiving of innovative infrastructure systems has the potential to revolutionize the civil engineering practice and widen the vision of civil engineering. Following this the analysis uwere carried out in ductile structural composites along with its enhanced properties, low maintenance coatings, better properties of cementitious materials, reducing the thermal transfer rate of fire retardant and insulation, various nanosensors, smart materials, intelligent structure technology etc. The properties like self-sensing, self-rehabilitation, self-cleaning, self-vibration damping, self-structural health monitoring and self-healing are the key features. To execute these, the gap between the nanotechnology and construction materials research needs to ube bridged. This paper first presents the background information and current developments in nanotechnology and civil engineering in general followed by the merits and demerits of their interdisciplinary approach. Further the details of application oriented nanotechnology-enabled materials and products that are either on the market or ready to be adopted in the construction industry and also their possible consequences over the time is elucidated. Some of the major instances of current applications of nanotechnology in the field of civil engineering across its different sections around the globe are exemplified. The most challenging economic factors concerned with its practicality are discussed briefly. Finally the future trend, potential and implications of nanotechnology development in civil engineering towards more economical infrastructure, low costmaintenance with longer durability are deliberated.

KEYWORDS:Civil Engineering, Nanomaterials, Nanotechnology,Sustainability

Copyright () 2014-2020 International Journal for Modern Trends in Science and Technology

DOI: https://doi.org/10.46501/IJMTST060701 


\section{INTRODUCTION}

BACKGROUND

As people involved in construction, we are very familiar with the concept of getting raw materials, bringing them together in an organized way and then putting them together into a recognizable form. The finished product is a passive machine. It works and slowly decays as it is used and abused by the environment and the owners of the project. Construction then is definitely not a new science or technology and yet it has undergone great changes over its history.

In the same vein, nanotechnology is not a new science and it is not a new technology either. It is rather an extension of the sciences and technologies that have already been in development for many years. The size of the particles is the critical factor. At the nanoscale (anything from one hundred or more down to a few nanometres, or 10-9 m) material properties are altered from that of larger scales. Another important aspect is that, as particles become nano-sized, the proportion of atoms on the surface increases relative to those inside and this leads to novel properties. It is these "nano-effects", however, that ultimately determine all the properties that we are familiar with at our "macro-scale" and this wis where the power of nanotechnology comes in - if we can manipulate elements at the nanoscale we can affect the macro-properties and produce significantly new materials and processes.

B.WHAT IS NANOTECHNOLOGY ? Nano, which comes from the Greek word for dwarf, indicates a billionth. One nanometre is a billionth of a metre. Definitions of 'nanotechnology' vary, but it generally refers to understanding and manipulation of matter on the nanoscale, say, from 0.1 run to 100 $\mathrm{nm}$. The significance and importance of controlling matter at the nanoscale is that at this scale different laws of physics come into play (quantum physics); There are two ways to approach the nanoscale: shrinking from the top down, or growing from the bottom up. The top down' approach entails reducing the size of the smallest structures towards the nanoscale by machining and etching techniques, whereas the 'bottom up' approach, often referred to as molecular nanotechnology, implies controlled or directed self-assembly of atoms and molecules to create structures

Addition of nanoscale materials into cement could improve its performance.use of nano-SiO2 could significantly increase the compression in concrete containing large volume of flyash and cement particles at nanoscale the despersion of amorphous nanosilica is used to remove segrigation resistance for self compacting concrete.

\section{C.NANOTECHNOLOGY IN CONSTRUCTION} The construction industry was the onlyindustry to identify nanotechnology as a promising emerging technology in the UK Delphi survey in the early 1990s [1]. The importance of nanotechnology was also highlighted in foresight reports of Swedish and UK construction [2-3]. Furthermore, ready mix concrete and concrete products were identified as among the top 40 industrial sectors likely to be influenced by nanotechnology in 10-15 years [4].However, construction has lagged behind other industrial sectors where nanotechnologyR\&D has attracted significant interest and investment from large industrial corporations and venture capitalists. Recognising the huge potential and importance of nanotechnology to the construction industry, the European Commission in late 2002 approved funding for the Growth Project GMA1-2002-72160 "NANOCONEX" Towards the setting up of a Network of Excellence in Nanotechnology in Construction.

\section{APPLICATIONS OF NANOTECHNOLOGY IN CIVIL ENGINEERING}

Nanotechnology can be used for design and construction processes in many areas since nanotechnology generated products have many unique characteristics. These 
characteristics can, again, significantly fix current construction problems, and may change the requirement and organization of construction process.

Some of its applications are examined in detail below:

\section{Advertisements}

\section{A.CONCRETE}

Concrete is one of the most common and widely used construction materials. Nanotechnology is widely used in studying its properties like hydration reaction, alkali silicate reaction (ASR) and fly ash reactivity [5]. Alkali silicate reaction is caused due to alkali content of cement and silica present in reactive aggregates like chert. The use of pozzolona in the concrete $\operatorname{mix}$ as a partial cement replacement can reduce the likelihood of ASR occurring as they reduce the alkalinity of a pore fluid. Fly ash not only improves concrete durability, strength and, importantly for sustainability, reduces the requirement for cement, however, the curing process of such concrete is slowed down due to the addition of fly ash and early stage strength is also low in comparison to normal concrete.

Addition of Nano-silica leads to the densifying of the micro and nanostructure resulting in improved mechanical properties. With the addition of nano- $\mathrm{SiO}_{2}$ part of the cement is replaced but the density and ustrength of the fly-ash concrete improves particularly in the early stages. For concrete containing large volume fly ash, at early age it can improve pore size distribution by filling the pores between large fly ash and cement particles at Nano scale. The dispersion/slurry of amorphous nano- $\mathrm{SiO}_{2}$ is used to improve segregation resistance for self-compacting concrete [6]. The addition of small amount of carbon nanotube $(1 \%)$ by weight could increase both compressive and flexural strength [7]. This can also improve the mechanical properties of samples consisting of the main portland cement phase and water. Oxidized multi-walled nanotubes (MWNT's) show the best improvements both in compressive strength $\left(+25 \mathrm{~N} / \mathrm{mm}^{2}\right)$ and flexural strength $\left(+8 \mathrm{~N} / \mathrm{mm}^{2}\right)$ compared to the reference samples without the reinforcement.

Cracking is a major concern for many structures. University of Illinois Urbana-Champaign is working on healing polymers, which include a microencapsulated healing agent and a catalytic chemical trigger. When the microcapsules are broken by a crack, the healing agent is released into the crack and contact with the catalyst. The polymerization happens and bond the crack faces. The self-healing polymer could be especially applicable to fix the micro cracking in bridge piers and columns. But it requires costly epoxy injection. Research has shown that an anaerobic (one that does not require oxygen) microorganism incorporated into concrete mixing water results in a $25 \%$ increase in 28-day strength. The Shewanella microorganism was used at a concentration of 105 cells $/ \mathrm{ml}$ and nanoscale observation revealed that there was a deposition of sand-cement matrix on its surface. This led to the growth of filler material within the pores of the cement sand matrix and resulted in increased strength.

Finally, fibre wrapping of concrete is quite common today for increasing the strength of pre-existing concrete structural elements. An advancement in the procedure involves the use of a fibre sheet (matrix) containing nano-silica particles and hardeners. These nanoparticles penetrate and close small cracks on the concrete surface and, in strengthening applications, the matrices form a strong bond between the surface of the concrete and the fibre reinforcement.

It is evident from the Fig. 1 that the SCCNFC (self consolidating concrete Nano fibre concrete) column failed at higher loads and with larger deflection than the SCRC (steel confined reinforced concrete) column. Additionally, the SCCNFC column was much stiffer than the SCRC column and higher exhibited energ dissipation. SCCNFC can also be used as a type of self- Structural Health Monitoring system. 


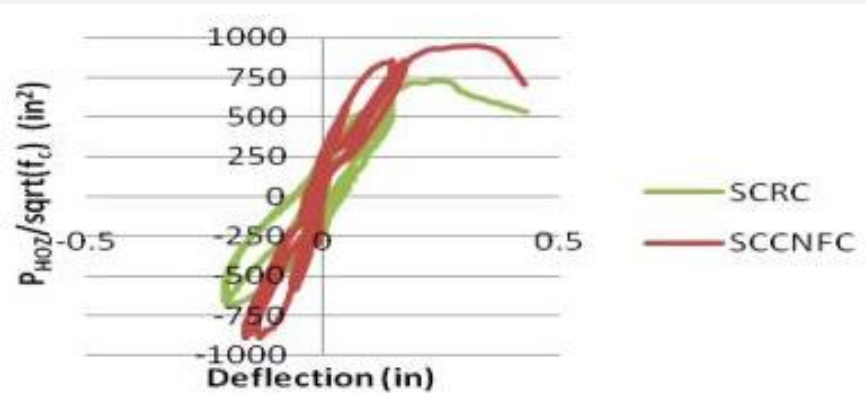

Fig. 1: Horizontal Force Vs Displacement Curves[17]

\section{B.STRUCTURAL COMPOSITES}

Steel is a major construction material. FHWA together with American Iron and Steel Institute and the U.S. Navy developed new, low carbon, high-performance steel (HPS) for bridges in 1992 with higher corrosion-resistance and weld ability by incorporating copper nanoparticles from at the steel grain boundaries [8].

Sandvik NanoflexTM is new stainless steel developed by Sandvik Nanoflex Materials Technology. Due to its high performance, it is suitable for application which requires lightweight and rigid designs. Its good corrosion, formability and wear resistance can keep life-cycle costs low [9] MMFX2 is nanostructure-modified steel, produced by MFX Steel Corp, USA. Compared with the conventional steel, it has a fundamentally different microstructure- laminated lath structure resembling "plywood" as shown in Fig.2. Due to the modified nanostructure, MMFX asteel has superior mechanical properties, e.g. higher strength, ductility and fatigue resistance, over other high-strength steels. These material properties can lead to longer service life in corrosive environments and lower construction costs. The MMFX2 steel has similar corrosion resistance to that of stainless steel, but at a much lower cost. So far, the MMFX steel has gained certification for use in general construction throughout the US.
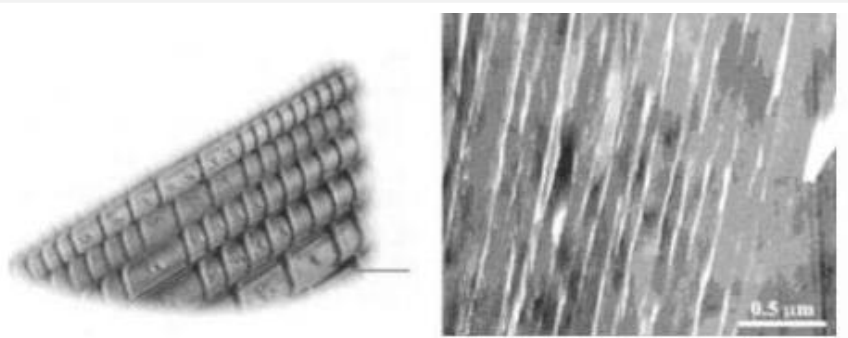

Fig. 2 Nanostructure modified steel reinforcement-TEM picture showing microstructure of nanosheet of austenite in a carbide free lath of martensite(MMFX of nano sheet Corp. USA[17]

Carbon nanotubes are over 100 times stronger than steel and only one-sixth of the weight in addition to its high thermal and electrical conductivities. A CNT composite has recently ubeen reported to be six times stronger than conventional carbon fibre composites [10]. Additionally, unlike carbon fibres which fracture easily under compression, the nanotubes are much more flexible and can be compressed without fracturing. CNT composite reinforced structures have a 50 - to 150-fold increase in tensile strength, compared with conventional steel-reinforced structures.

\section{COATINGS}

The coatings incorporating certain Nano particles or Nano layers have been developed for certain purpose including: protective or anti-corrosion coatings for components; self-cleaning, thermal control, energy saving, anti-reflection coatings for glass/windows; easy-to-clean, antibacterial coatings for work surfaces; and more durable paints and anti-graffiti coating for buildings and structures. For example: Self-cleaning windows have ubeen developed and marketed by Pilkington, St. Gobain Co., and others [11]. This coating works in two stages. First, using a 'photocatalytic' process, nanosized $\mathrm{TiO}_{2}$ particles in the coating react with ultra-violet rays from natural daylight to break down and disintegrate organic dirt. Secondly, the surface coating is hydrophilic, which lets rainwater spread evenly over the surface and 'sheet' down the glass to wash the loosened dirt away. It can therefore reduce airborne pollutants when applied to outdoor surfaces. Coating of $7000 \mathrm{~m}^{2}$ of road 
surface with such a material in Milan in 2002 has led to a $60 \%$ reduction in nitrogen oxides concentration at street level. Research has also demonstrated that bimetallic Nano particles, such as $\mathrm{Fe} / \mathrm{Pd}, \mathrm{Fe} / \mathrm{Ag}$, or $\mathrm{Zn} / \mathrm{Pd}$, can serve as potent reductants and catalysts for a large variety of environmental contaminants [12].

Another approach to create self-cleaning surface coating has been the development of 'Lotus Spray' products by BASF u[13], based on ideas of replicating the spotless lotus leaves. The product offers 20 times more water-repellent property than a smooth, wax coating. With its applications in the construction industry, the company aims to develop a product that will retain its lotus effect even after an abrasion with sandpaper.

Special coatings can also make the applied surface both hydrophobic and oleophobic at the same time. These could be used for anti-graffiti surfaces, carpets and protective clothing etc. Researchers in Mexico has successfully developed a new type of anti-graffiti paint DELETUM, by functionalising nanoparticles and polymers to form a coating repellent to water and oil at the same time, as shown in Fig. 3.

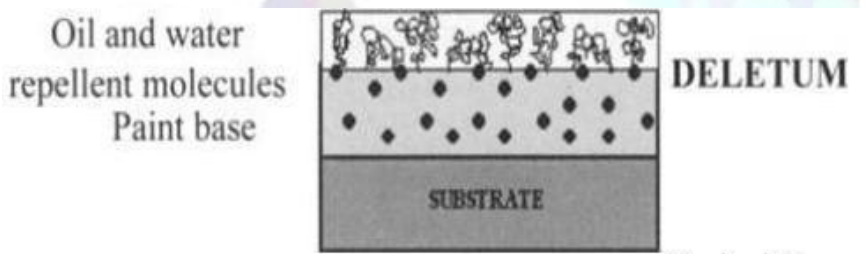

Fig. 3: Stratigraphy of Deletum anti-graffiti coating[17]

As a result, the coated surface is non-stick or very easy to clean, and able to withstand repeated graffiti attacks. Furthermore nanostructured coatings can be used to selectively reflect and transmit light in different wavebands [14]. Research is focusing on smart and responsive materials able to sense and adapt to surroundings and change their appearance, such as whose colour changes as a function of temperature, and cladding which responds to heat and light to minimise energy use in buildings

\section{GLASS}

Fire-protective glass is another application of nanotechnology. This is achieved by using a clear intumescent layer sandwiched between glass panels (an interlayer) formed of fumed silica $\left(\mathrm{SiO}_{2}\right)$ nanoparticles which turns into a rigid and opaque fire shield when heated. The electrochromic coatings are being developed that react to changes in applied voltage by usinga tungstenoxide layer; thereby becoming more opaque at the touch of a button. Because of the hydrophobic properties of $\mathrm{TiO}_{2}$, it can be applied in antifogging coatings or in self-cleaning windows . Nano- $\mathrm{TiO}_{2}$ coatings can also be applied to building exteriors to prevent sticking of pollutants, and thus reduce a facility's maintenance costs [15].

\section{E. NANOSENSORS}

Nanotechnology enabled sensors/devices also offer great potential for developing smart materials and structures which have 'self-sensing' and 'self-actuating' capability. The device used for air bags in cars is such an example. Nano and Micro electrical mechanical systems (NEMS \& MEMS) sensors have

been developed and used in construction to monitor and/or control the environment conditions (e.g. temperature, moisture, smoke, noise, etc.) and the materials/structure performance (e.g. stress, strain, vibration, cracking, corrosion, etc.) during the structure's life. Nano sensor ranges from $10^{-9} \mathrm{~m}$ to $10^{-5} \mathrm{~m}$ which could be embedded into the structure during the construction process.

Cyrano Sciences has developed electronic noses based on an array of different polymer nanometre-thin film sensors [16]. Siemens and Yorkshire Water are developing autonomous, disposable chips with built-in chemical sensors to monitor water quality and send pollution alerts by radio . Smart aggregate, a low cost piezoceramic-based multi-functional device, has been applied to monitor early age concrete properties such as moisture, temperature, relative humidity and early age strength development [16]. Also it can 
provide an early indication before a failure of the structure occurs.

\section{F. BULK INSULATING MATERIALS}

NanoPore has developed bulk nanoporous silica compounds with embedded organic molecules which perform up to 10 times better than conventional insulating materials . The superior insulation characteristics of these low density, highly porous solids are due to the unique shape and small size (10-100 nm) of its large number of pores. So far, these new insulating compounds have been used in applications that require excellent thermal performance, optimum energy efficiency, or minimum insulation thickness.

Advertisements

\section{G. PLASTICS}

The carbon fibre reinforced plastics (CFRP) being light weight material does not exhibit good electrical properties. CNTs are among the stiffest and strongest fibers known, and have high electrical conductivity. At IFAM in Bremen, researchers employed plasma technology in order to transfer their properties to CFRPs since these micro- or nanoparticles must be highly homogeneous, and sometimes very closely bound to the polymer. Dr. Jörg Ihde, explains: "We spray the particles i.e. the nanotubes into this atmospheric plasma." They immediately fall into the selected solvent, which ucan then ube used to further process the polymer. The whole procedure takes just a few useconds". This can be pressed onto an electronic component so heat is dissipated directly.

\section{H. PLASTIC SOLAR}

CELL

The most promising application in the areas of energy and environment leading to the sustainable building is the development of fuel cells and photovoltaic. In the last few years, considerable efforts have been made to develop plastic solar cells in Fig. 4, much simpler and cheaper to produce than that of conventional silicon semiconductor solar cells. Replacing conventional lamps with LEDs in the United States alone could generate energy savings of up to $\$ 100$ billion by 2025 and reduce carbon emissions by 200 million tons per year.

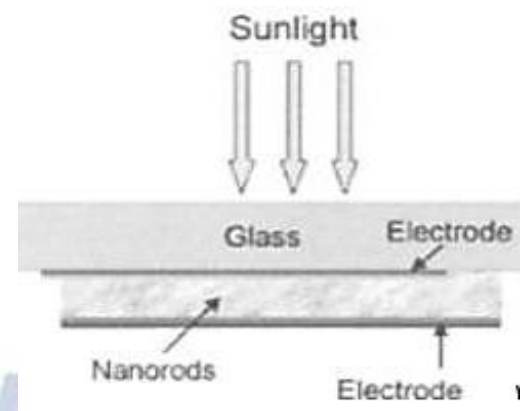

Fig. 4: Schematic diagram of a hybrid "plastic" solar cell with a nanorod/polymerlayer sandwiched between two electrodes. The middle layer, a mere $200 \mathrm{~nm}$ thick, is a jumble of nanorods embedded in the semiconducting polymer[17]

I. BITUMEN

The bentonite (BT) and organically modified bentonite (OBT) were used to reinforce and modify asphalt binder by melt processing under sonication and shearing stresses. The BT modified asphalt possess intercalated structure while OBT modified asphalt possessed exfoliated structure. The BT and OBT modified asphalts have shown greater softening point, viscosity, higher complex modulus, lower phase angle and higher rutting parameter and better rheological properties than the base asphalt. But the ductility of the modified asphalts decreased with the addition of BT and OBT. They have significantly lower creep stiffness. Therefore, the low temperature cracking resistance was improved by addition of BT and OBT. The OBT modified asphalts has better properties than the BT modified asphalts.

\section{J. BIOMIMETIC MATERIALS}

Biomimetics is the science of mimicking nature, and biomimetic materials seek to replicate the best features of natural materials. Examples such as honeycomb giving a lightweight structure with exceptional mechanical strength, antler bone being tougher than any man-made ceramic composites, lotus leaf giving self-cleaning surfaces, hameleon's skin changing colours with the environment, etc. By manipulating materials at the atomic level enabled by nanotechnology advances, biomimetic materials research 
provides a productive approach of new materials and molecular manufacturing.

\section{K. SMART MATERIALS}

Smart materials are materials with properties engineered to change in a controlled manner under the influence of external stimuli like temperature, force, moisture, electric charge, magnetic fields and $\mathrm{pH}$. Examples are Piezoelectrics, Thermoresponsives, Shape Memory Alloys (SMA), Polychromic, Chromogenic materials etc. Like piezoelectrics that alter their shape under the influence of the electric field, SMA change shape due to magnetic fields. Intelligent Reinforced Concrete Structure (IRCS) is conceptualised on them. The UIRCS has multiple functions which include self-rehabilitation, self-vibration damping, and self-structural health monitoring. In this a special type of piezoceramic called PZT (lead zirconate titanate), which possesses a strong piezoelectricity effect, and a special type of SMA called Nitinol, which has good corrosion resistance and large actuation stress, will be used. The proposed concrete structure is reinforced by martensite Nitinol cables using the method of post-tensioning. The martensite Nitinol significantly increases the concrete's damping property and its ability to handle large impact. In presence of cracks due to explosions or earthquakes, by electrically heating the SMA cables, the SMA cables contract and close up the cracks. To detect possible cracks inside the concrete structure, a PZT patch is used as an actuator to generate waves and other distributed PZT patches are used as sensors to record the received vibration signals.

\section{NANOTECHNOLOGY} PROTECTION

FIRE

Fire resistance of steel structures is often provided by a coating of spray on cementitious process which is no more popular because they need to be thick, tend to be brittle and polymer additions are needed to improve adhesion. However, research into nano-cement (made of nano-sized particles) has the potential to create a new paradigm in this area of application. This is achieved by the mixing of carbon nanotubes (CNT's) with the cementious material to fabricate fibre composites that can inherit some of the outstanding properties of the nanotubes such as strength. Polypropylene fibres are also being considered as a method of increasing fire resistance and this is a cheaper option than conventional insulation. CNTs can also be used to produce protective clothing materials because of their flame retardant property.

\section{IMPACTS OF NANOTECHNOLOGY ON CONSTRUCTION}

\section{A. MERITS}

1) Compared with conventional $\mathrm{TiO}_{2}, \mathrm{TiO}_{2}$ at the nano-scale experiences a 500\% increase in surface area and a 400\% decrease in opacity. Current nano- $\mathrm{TiO}_{2}$ production levels have reached approximately 4 million metric tons at a price of approximately $\$ 45 / \mathrm{kg}$ to $\$ 50 / \mathrm{kg}$ vs. $\$ 2.5 / \mathrm{kg}$ for conventional $\mathrm{TiO}_{2}$.

2) The CNT market worldwide is expected to grow from $\$ 51$ million in 2006 to more than $\$ 800$ million by 2011 (BCC Research 2008).

3) Nano-modified concrete cuts down construction schedules while reducing labour-intensive (and expensive) tasks. Also it can reduce the cost of repair and maintenance.

4) The paint and coatings industry consists of approximately annual sales of $\$ 20$ billion (Baer et al. 2003). Nano-alumina and titania have a four- to six-fold increase in wear resistance, with doubled toughness and bond strength (Gell 2002).

5) The potential global market of nanocomposites is estimated at $\$ 340$ billion for the next two decades (Roco and Bainbridge 2001).

6) The market for fire protection systems totalled approximately $\$ 45$ billion in 2004 and is expected to grow to more than $\$ 80$ billion by 2010 (Helmut Kaiser Consultancy 2008)

7) Self-repairing asphalt, healing and rejuvenating nanoagents for asphalt (Partl et al. 2006), and self-assembling polymers improve asphalt mix.

8) Nano sensors embedded in infrastructural materials can provide, at minimum cost, fully integrated and self-powered failure 
prediction and forecasting mechanisms for high-capital structures (e.g., reservoirs, nuclear power plants, and bridges).

\section{B. DEMERITS}

1) Because of their small particle size, nano particles have the potential to negatively affect the respiratory and digestive tracks and the skin or eye surface [4] thus exposes workers to hazards.

2) Since nanotechnology-related industries are relatively new, the type of uworker who is employed in construction research and development (or even some field applications) must have an interdisciplinary background.

3) New policies in the context of nanotechnology will require cooperation between various levels of government, R\&D agencies, manufacturers, and other industries.

4) Small production volumes and high cost remain the main barriers to the use of nanotechnology (The Royal Society 2004)

5) The time for commercializing a product is long. E.g. the concrete, which can eliminate the need for reinforcing bars, is projected to be commercialized by approximately 2020 .

\section{SUSTAINABLECONSTRUCTION}

At an annual production rate of 2.35 billion tons, the cement industry contributes about $5 \%$ to global anthropogenic $\mathrm{CO}_{2}$ emissions. Additives such as belite, calcium sulfo-aluminate and calcium ualumino-ferrite (BASF 2008) have been found to reduce the $\mathrm{CO}_{2}$ emissions by nearly $25 \%$ in the production phase

A wall made of nano-modified concrete during a cold weather season could potentially be used as a thermal insulator when the outside temperature falls or used as a conductor when the ambient temperature inside the building is low, thereby reducing the energy load required for conditioning the building interior.

With further development of LED \& OLED technology and progress in the insulating materials and smart glazing, the vision for buildings to meet their own energy requirement will become a reality.

\section{FUTURE PROJECTION OF NANOTECHNOLO GY IN CONSTRUCTION}

There is substantial money flowing into nano-related research from multinational corporations and venture capital investments [4, 16]. Many of the world's largest companies such as IBM, Intel, Motorola, Lucent, Boeing, Hitachi, etc. have all had significant Nano-related research projects going on, or launched their own nanotech initiatives. By 2015, the National Science Foundation estimates that nanotechnology will have a $\$ 1$ trillion effect on the global economy. To achieve this market-sized prediction, industries will employ nearly two million workers towards advancements in many Nano materials, Nano structures, and Nano systems. The time needed for commercializing a product is long because industries may prefer monitoring development in research agencies and laboratories before making substantial investments. Furthermore, nanotechnology development, particularly in conjunction with biomimetic research will lead to truly revolutionary approaches to design and production of materials and structures with much improved efficiency, sustainability and adaptability to changing environment.

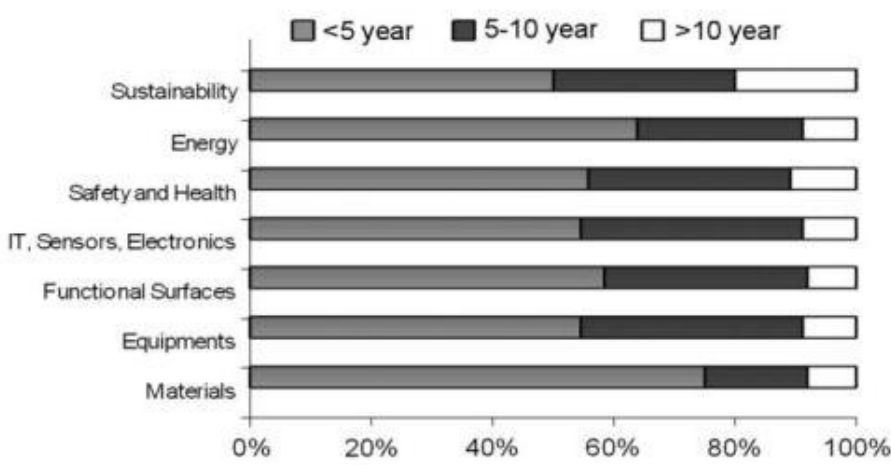

Fig. 5: Expected successful implementation of nanotechnology products in construction[17] VI. CONCLUSION

Research in nanotechnology that is related to construction is still in its infancy; however, this paper has demonstrated the main benefits and barriers that allow the effect of nanotechnology on construction to be defined. Recent years of R\&D have shown massive investments 
Nano-construction. The activities in Nano related products for the construction industry are not well marketed and are difficult for industry experts to identify. A large-scale and visible initiative from nano-science and nanotechnology in the construction area could help seed construction related nano-technological development. Focused research into the timeous and directed research into nanotechnology for construction infrastructure should be pursued to ensure that the potential benefits of this technology can be harnessed to provide longer life and more economical infrastructure. This paper concludes with a roadmap and strategic action plan on how nanotechnology can have its biggest impact on the field of civil engineering.

\section{REFERENCES}

[1] Bartos, Roadmap-novel materials." Centre for Nanomaterials Applications in Construction, Bilbao, Spain "http://www.mmsconferencing.com/nanoc/" (Jan. 13, 2008).

[2] Shah, S. P., and A. E. Naaman. "Mechanical Properties of Glass and Steel Fiber Reinforced Mortar." ACI Journal 73, no. 1 (Jan 1976): 50-53.

[3] Saafi, M. and Romine, P. (2005)."Nano- and Microtechnology." Concrete International, Vol. 27 No. $12, \quad$ p $28-34$.

[4] Baer, D. R., Burrows, P. E., and El-Azab, A. A. (2003). "Enhancing coating functionality using nanoscience and nanotechnology." Prog. Org. Coat., 47(3-4), 342-356.

[5] Balaguru, P. N., "Nanotechnology and Concrete: Background, Opportunities and Challenges." Proceedings of the International Conference Application of Technology in Concrete Design, Scotland, UK, p.113-122, 2005.

[6] Lau, Kin-Tak, and David Hui. "The revolutionary creation of new advanced materials-carbon nanotube composites."Composites: Part B 33, no. 4 (2002): 263-277.

[7] Mann, S. (2006). "Nanotechnology and Construction," Nanoforum Report. www.nanoforum.org, May 30, 2008.

[8] ASCE. (2005). "Report card for America's infrastructure. American society of civil engineers" "http://www.asce.org"(Mar. 8, 2008).

[9] Sobolev, K. and Gutierrez, M. F. (2005). "How Nanotechnology can Change the Concrete World," American Ceramic Society Bulletin, vol. 84, no. 10, p. 14-16.

[10] Baughman, R. H., Zakhidov, A. A., and de Heer W. (2002). "Carbon nanotubes- The route toward applications.” Science, 297(5582), 787-792.
[11] Pilkington, http://www.activglass.com/.

[12] BASF,http://www.basf.de

[13] Castano, V.M. and Rodriguez, R, 'A nanotechnology approach to high performance anti-graffiti coatings'., London, Oct. 2003

[14] Goddard III, W.A., Brenner, D.W., Lyshevski, S.E. and Iafrate, G.J. "Properties of High-Volume Fly Ash Concrete Incorporating Nano-SiO2." Cement and Concrete Research, vol.34, p.1043-1049, 2004.

[15] Beatty, C. (2006). "Nanomodification of asphalt to lower construction temperatures." NSF Workshop on Nanotechnology, Material Science and Engineering, National Science Foundation, Washington, DC.

[16] PCI, TR-6-03. Interim Guidelines for the Use of Self-Consolidating Concrete in Precast/ Chicago: Concrete Institute, 2003.

[17] www.engineeringcivil.com
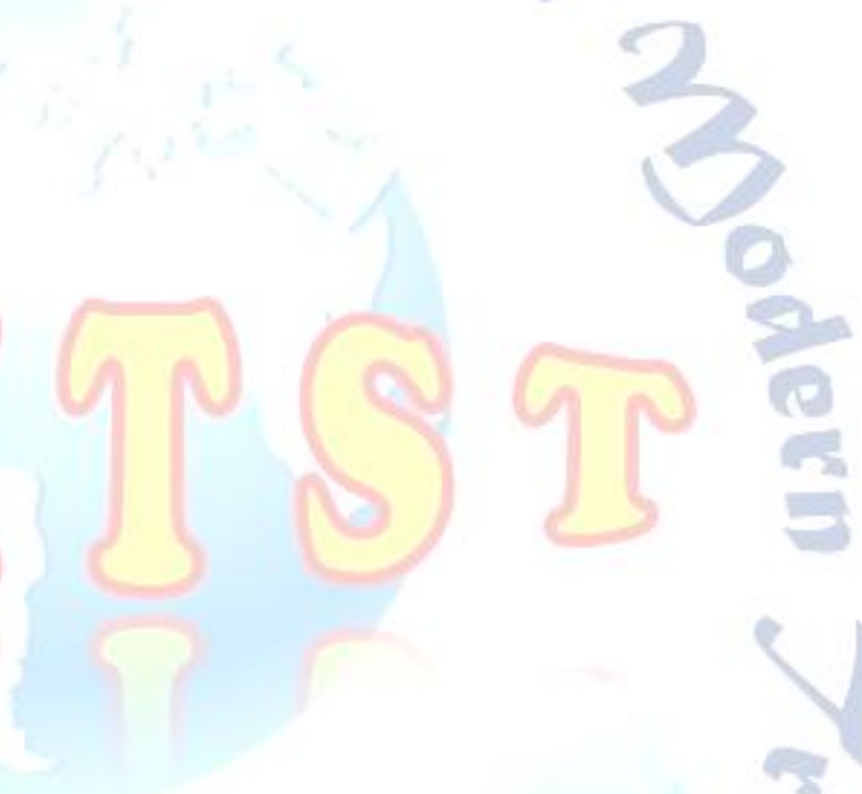